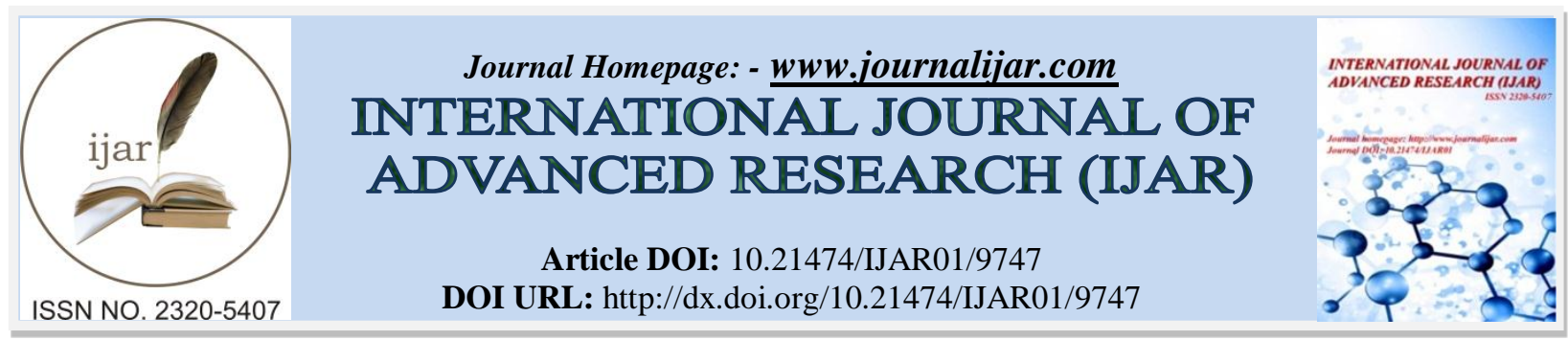

RESEARCH ARTICLE

\title{
GLYPHOSATE AND PENDIMETHALIN IN BREAST MILK SAMPLES FROM EGYPTIAN RURAL AREAS: A PILOT STUDY FOR INFANT'S RISK ASSESSMENT.
}

Khaled Y. Abdel-Halim ${ }^{1}$, Mohamed A. F. Abuzeid ${ }^{2}$, Fayza A. Seddik ${ }^{3}$ and Alaa M. Khozimy ${ }^{2}$.

1. Mammalian \& Aquatic Toxicology Department, Central Agricultural Pesticides Laboratory (CAPL), Agricultural Research Center (ARC), 12618-Dokki, Giza, Egypt.

2. Department of Plant Protection, Faculty of agriculture, Damanhur University, 22516-Damanhur, Egypt.

3. Pesticide Residues \& Environmental Pollution Department, Central Agricultural Pesticides Laboratory (CAPL), ARC, 12618-Dokki, Giza, Egypt.

\section{Manuscript Info}

Manuscript History

Received: 12 July 2019

Final Accepted: 14 August 2019

Published: September 2019

Key words:-

herbicides; human milk; rural region; risk assessment.

\section{Abstract}

Thirty-one samples of breast milk were collected from some rural mothers and conducted for herbicides; glyphosate and pendimethalin analysis followed by their impact on infants. Three rural locations; Shobrakhite, Abo Homos and Abo El-Matamir in El-Behira governorate were selected for the study as well as an urban location in Alexandria as a reference. Glyphosate and pendimethalin exhibited ranges of concentrations; 3.25-27.91; below detection limit-8.91; below detection limit-10.11 $\mu \mathrm{g} / \mathrm{ml}$ and $1.44-21.62 ; 2.51-15.94 ; 1.88-24.02$ $\mu \mathrm{g} / \mathrm{ml}$ for Shobrakhite, Abo Homos and Abo El-Matamir locations, respectively. High vegetables and cereal consumption by mothers showed higher herbicide-contaminated milk $\left(r=0.273^{*}\right.$ and $\left.0.24^{*}\right)$ than others. On the other hand, herbicides were negatively associated with young and house wife individuals $\left(\mathrm{r}=-0.272^{*}\right.$ and $\left.-0.330^{*}\right)$. Tolerable daily intakes for infants were addressed for rank of low, moderate and high exposure. Infants of Abo El-Matamir location exhibited the greatest value for pendimethalin, but group of Shobrakhite location exhibited the greatest value for glyphosate. The present findings indicate that, signs alarms of adverse health effects of herbicides may be imposed on these infants and their families.

Copy Right, IJAR, 2019,. All rights reserved.

\section{Introduction:-}

Pendimethalin [N-(1-ethlpropyl)-3, 4-dimethyl-2, 6-dinitrobenzamine); CAS 40487-42-1] is a dinitroaniline herbicide that selectively used against certain broad leaf and grassy weeds in variety of crops and in non-crop areas. Pendimethalin predominantly applied to soil as pre-emergence, but sometimes used as post emergence and has been marketed for 30 yrs. It is used on fruit, grapes, vegetables, oil seeds, cereals, tobacco and ornamentals crops (European Community, 2003). On the other hand, glyphosate [N-(phosphonomehyl) glycine; CAS Number 107183-6] is a broad-spectrum systemic herbicide and crop desiccant. It is used to kill weeds, especially annual broadleaf weeds and grasses that compete with crops. In 2007, glyphosate was the most used herbicide in the United States, agricultural sector and the second-most used in gardens, industry, and commerce. Since 2016, there was 100-fold increase for the late 1970s in the frequency of application and volume of glyphosate-based herbicides (GBHs) applied, with further increases expected in the future partly in response to the global emergence and spread of 
glyphosate-resistant weed (Myers et al., 2016). In Egypt, it is extensively used to control weeds on beans, grapes, citrus crops, and to control annual and biannual weeds

El-Behira governorate is located between Alexandria and Kafr El-Sheikh in Northern Delta of Egypt with an area of $103.28 \mathrm{E} 03 \mathrm{Km}^{2}$. The percentage of cultivated area to the total area is $61 \%$. The main cultivated crops are wheat, clover, sugar beet, rice, cotton, maize, soybean, fruits, and vegetables (Khalil et al., 2011). The recorded amount of pesticides used in Egypt during 2016 was 9965.79 metric ton active ingredients, so 2453.86 of them were recorded for weed control (APC, 2007). During and after application of pesticides, they can spread through environmental components and distribute far from application site. As a result, rural residents may be highly exposed to these compounds through consumption of contaminated crops and diet and/or environmental exposure.

Adverse effects of pesticides to human health have been described in the literature. Residue of pesticides in breast milk is a concern since infants do not have a fully developed detoxication mechanisms, where their immune systems and other organs are immature and milk is considered the best sole nutrient source (Pignati et al., 2007). Breast feeding is considered as one of the major excretion pathway of toxicants from mother to infants, resulting into pesticides transfer to newborns. Generally, breast milk-fed newborns are greater immunity, normal growth, better digestive process, better emotional and nervous system development than others. World Health Organization (WHO) stated that, breastfeeding reduces child mortality and has health benefits that extend into adulthood. Breast milk (3-5\% fat) is an aqueous fluid, whose characteristics allow it to uptake both hydrophilic and lipophilic compounds. Human milk is also a unique biological matrix for monitoring certain environmental contaminants because it can provide exposure information about both the mother and breastfed infant through non-invasive method of collection. Recently, the literature stated that different kinds of pesticide residues were found in breast milk in worldwide (Bouwman et al., 2006; Feo et al., 2012). For example, organochlorine pesticides were the mostly excreted group via breast milk. Excretion of these compounds via human milk exposes breast-feeding infants to a variety of organochlorine pesticides, especially in agricultural areas, where they were most often used. As documented, human milk is one route of elimination for the mother's body burden, but unfortunately that route also increases the exposure of infants (Jensen and Slorach, 1991). There have been many surveys of pesticides in human milk-some in response to episodes of food or dairy product contamination. The data from these surveys have been used to compare pesticide concentrations in human milk to establish allowable daily intakes. In most literature sites, organophosphates, polycyclic aromatic hydrocarbons, polychlorinated biphenyls compounds, as well as heavy metals showed positively measurements in human milk samples from different countries (Sonawane, 1995). On the other hand, most of non-halogenated organic chemicals are not very persistent, either in the environment or in the human body. Thus, detectable levels of such substances in human milk are usually found when the exposure is high and long-term in nature, as in the occupational environment. For example, an investigation concern 51 milk samples, from 13 nursing mothers in the United States, 16 samples contained measurable levels (0.1-1.1 ppb) of Nnitrosodimethylamine. In certain individuals, eating a meal of bacon and a vegetable high in nitrate occasionally resulted in higher levels of nitrosamine in their milk (Lakritz and Pensabene, 1984). However, there is a lack in literature concerning herbicides monitoring in human milk.

Solid-phase, liquid-liquid partition, and sonication extraction techniques have been used for extraction and clean-up of breast milk samples followed by analyte measurements on high performance liquid chromatography with diode array and fluorescence detector and confirmed on mass spectrometry (Burke et al., 2003; Manaca et al., 2011). Most published techniques propose to determine isolated compounds or multi with similar physical and chemical properties. The selected method is able to determine molecules with different properties, since humans are exposed to different classes of pesticides. Thus, the study aimed to evaluate the risk of excessive use of herbicides for breastfed infants in correlation with their mother's characteristics in some rural areas of Delta, Egypt.

\section{Material and Methods:-}

\section{Reagents and chemicals}

High purity standards of herbicides; pendimethalin and glyphosate were obtained from Sigma Aldrich Chemie $\mathrm{GmbH}$ (Steinheim, Germany). Stock standard solutions were prepared in acetonitrile for chromatography and mass spectrometric analysis. Acetone, $n$-hexane, acetonitrile, toluene, anhydrous sodium sulphate and Celite ${ }^{\circledR}$ filter aide, with analytical grade were obtained from BDH Chemical Ltd Co. Trifluoroacetic anhydride (TFAA) and 1methylimidazole were obtained for Aglient technology, Japan. 


\section{Sampling collection and analysis} Study regions

A total of thirty-one (31) nursing mothers were randomly selected for the study from three rural locations of ElBehira governorate; Shobrakhite, Abo Homos and Abo El-Matamir. Another location in Alexandria was selected as a reference zone (Fig. 1). The participants were conducted to fill a questionnaire based on personal information and diet status as well as their infant's information. Ethical report; IORG\#..IORG0008812 was provided by Ethical Committee of Medical Research Institution, Alexandria University, Egypt. The human breast milk samples were collected in sterilized Falcone tube $(45 \mathrm{ml})$, transferred to the laboratory in ice box and stored at $-20{ }^{\circ} \mathrm{C}$ prior to analyses.

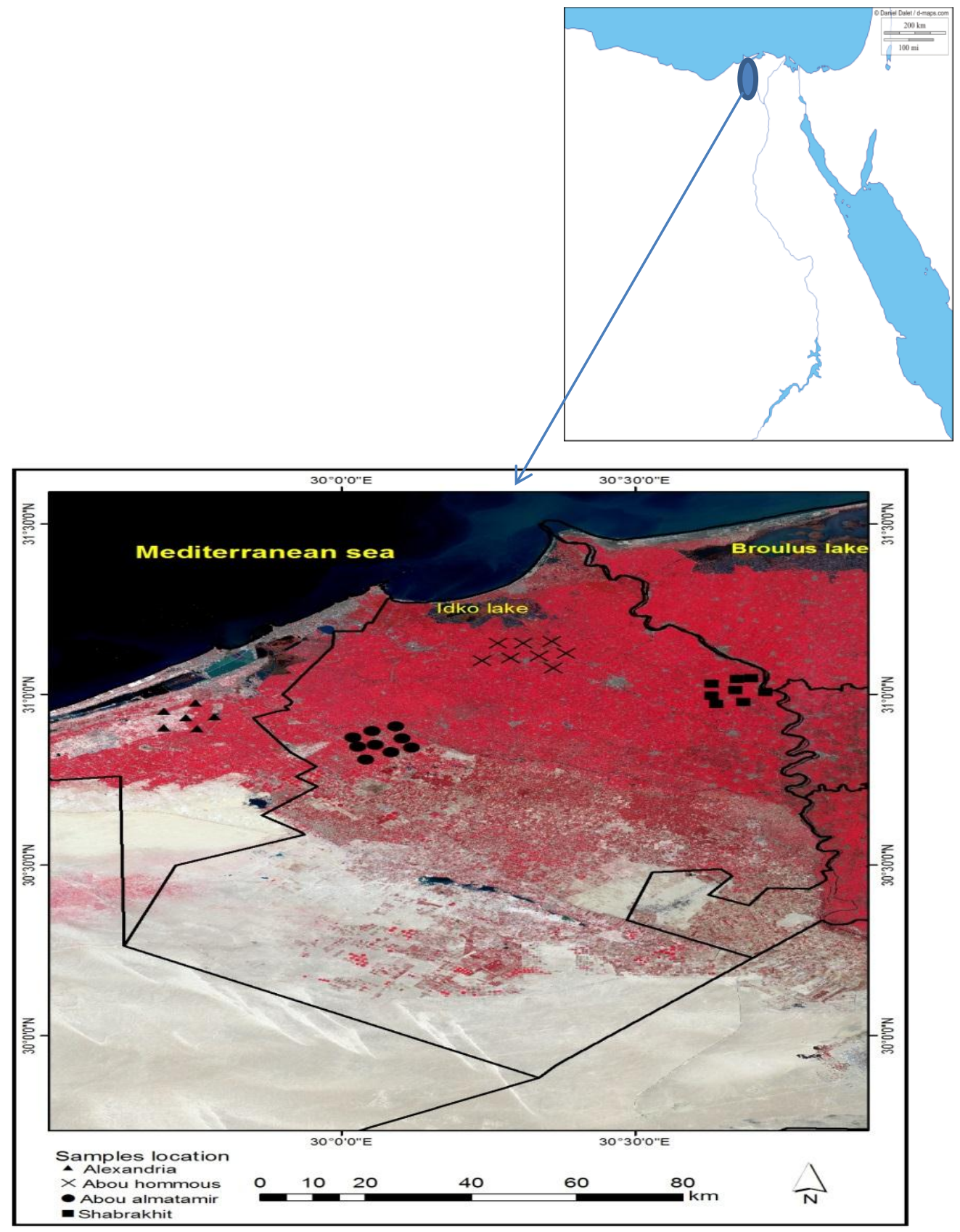

Fig 1:-Google map showing human milk sampling sites from El-Behira governorate, Egypt. 


\section{Analytical procedures}

Five $\mathrm{ml}$ of breast milk were mixed with deactivated Celite ${ }^{\circledR}\left(600{ }^{\circ} \mathrm{C}\right.$ for $\left.12 \mathrm{hr}\right)$ in $100 \mathrm{ml}$ centrifuge tube. Ten $\mathrm{ml}$ of each solvent system: I ( $n$-hexane: acetone $1: 1 \mathrm{v} / \mathrm{v})$; II $(n$-hexane) and III $(n$-hexane: acetonitrile 1:1 v/v), respectively, were added. The resulting mixture was agitated by sonication during $20 \mathrm{~min}$ followed by centrifugation (2000 rpm; $5 \mathrm{~min}$ ) for phase's separation. The extraction procedure was repeated. All supernatants were combined, evaporated to dryness and dissolved in $1 \mathrm{ml}$ toluene (Palma et al., 2014).

Fluorescent derivatiztion of glyphosate was performed according to method of Diserens and Henzelin (1999). Half $\mathrm{ml}$ of each sample was mixed with $300 \mu \mathrm{l}$ of trifluoroacetic anhydride $+200 \mu 1$ of 1-methylimidazole in reaction vail which sealed with a stopper and mixed well on vortex mixer. The mixture was incubated at $60{ }^{\circ} \mathrm{C}$ for $1 \mathrm{hr}$.

Analytes were identified and quantified using High Performance Liquid chromatography (HPLC; Agilent technologies 1260, USA) equipped with an analytical column $\mathrm{C}_{18}$ at room temperature. The mobile phase was used as methanol: acetonitrile $1: 1 \mathrm{v} / \mathrm{v}$ at a flow rate $1 \mathrm{ml} / \mathrm{min}$. Pendimethalin was subjected to diode array detector at 265 $\mathrm{nm}$, but glyphosate was subjected on fluorescence detector with excitation wavelength $532 \mathrm{~nm}$ and emission wavelength $488 \mathrm{~nm}$.

\section{Analytical method validation}

The efficiency of the method was conducted via recovery experiment and precision (Coefficient of variation of the results obtained in duplication). The limits of detection (LODs) of the method was calculated according to criteria established by Thier and Zeumer (1987). Acceptable recovery percentages were 90.2 and $73.16 \%$ for pendimethalin and glyphosate with an associated repeatability [Coefficient of variation (CV)] $\leq 20 \%$. Analytes were identified by comparison with retention times of the standard and were quantified with standard solutions.

\section{GC-Mass spectrometry}

To confirm the results obtained from HPLC measurement, GC-MS was used. Samples of pendimethalin were measured directly, but others of glyphosate were employed to derivatization as described above. The instrument used was GC-MS (Agilent technologies 7890D GC and Agilent technologies 5977A MSD) equipped with HP 5MS (30 $\mathrm{m} \times 0.25 \mathrm{~mm} \times 0.25 \mu \mathrm{m}$ film thickness). Helium was used at a flow rate of $2 \mathrm{ml} / \mathrm{min}$. The injection temperature was $160{ }^{\circ} \mathrm{C}$. The initial oven temperature was $160{ }^{\circ} \mathrm{C}$ and increased to $320{ }^{\circ} \mathrm{C}$ at $6{ }^{\circ} \mathrm{C} / \mathrm{min}$ and held for $2 \mathrm{~min}$. The mass selective detector was operated in EI (electron impact ionization) mode and SIM (selective ion monitoring) mode.

Tolerable daily intake (TDI)

Daily intake of measured herbicides by infants was calculated based on the assumption that the average milk consumption of a $5 \mathrm{~kg}$ infant was $250 \mathrm{ml} /$ day (estimated). TDI of herbicides was estimated as follows:

$$
T D I=C \times R t \times \frac{C f}{B w}
$$

Where TDI was estimated as $\mathrm{mg} / \mathrm{kg}$ bw/day, $\mathrm{C}$ is the concentration of herbicide ( $\mathrm{mg} / \mathrm{ml} \mathrm{milk).} \mathrm{Rt} \mathrm{is} \mathrm{the} \mathrm{consumption}$ rate, $\mathrm{Cf}$ is the lipid content \% (estimated) and $\mathrm{Bw}$ is the average body weight of infants $(\mathrm{kg})$.

\section{Statistical analyses.}

Statistical analyses were performed using COSTAT, Costat User Manual, Version 3. Tucson, Arizona, USA (Cohort Software Inc., 1985). Data were conducted using IBM SPSS statistics 19.0 (SPSS Inc., Chicago, IL, USA).

\section{Results:- \\ Herbicide concentrations}

The concentrations of herbicides; pendimethalin and glyphosate were measured in breast milk samples collected from three rural locations of El-Behira governorate (Table 1). Samples of Abo El-Matamir location exhibited a range 1.88-24.02 $\mu \mathrm{g} / \mathrm{ml}$ for pendimethalin with mean \pm SE concentration; $8.05 \pm 0.80 \mu \mathrm{g} / \mathrm{ml}$. On the other hand, their range for glyphosate was BDL-10.11 $\mu \mathrm{g} / \mathrm{ml}$ with mean concentration; $5.24 \pm 0.37 \mu \mathrm{g} / \mathrm{ml}$. The samples collected from Shobrakhite location exhibited a range 1.44-21.63 $\mu \mathrm{g} / \mathrm{ml}$ for pendimethalin with mean concentration; 5.56 \pm 0.86 $\mu \mathrm{g} / \mathrm{ml}$. Their range for glyphosate herbicide was $3.25-27.91 \mu \mathrm{g} / \mathrm{ml}$ attributing mean concentration; $12.66 \pm 1.19$ 
$\mu \mathrm{g} / \mathrm{ml}$. Pendimethalin concentrations in samples of Abo Homos location ranged from 2.51 to $15.94 \mu \mathrm{g} / \mathrm{ml}$ with mean value; $7.80 \pm 0.49 \mu \mathrm{g} / \mathrm{ml}$, but the range for glyphosate was BDL-8.19 $\mu \mathrm{g} / \mathrm{ml}$ attributing mean concentration; $6.38 \pm 0.28 \mu \mathrm{g} / \mathrm{ml}$. Alexandria location conducted samples with concentrations lower than those of rural locations arising ranges (BDL-5.30 $\mu \mathrm{g} / \mathrm{ml})$ and (3.04-6.98 $\mu \mathrm{g} / \mathrm{ml})$ for pendimethalin and glyphosate, respectively.

Table 1:-Herbicide concentrations $(\mu \mathrm{g} / \mathrm{ml})$ in breast milk samples of some Egyptian rural residents.

\begin{tabular}{|c|c|c|c|c|c|}
\hline \multirow[t]{2}{*}{ location } & \multirow[t]{2}{*}{ (n) } & \multicolumn{2}{|c|}{ Pendimethalin } & \multicolumn{2}{|c|}{ Glyphosate } \\
\hline & & range & mean \pm SD & range & mean \pm SD \\
\hline Shobrakhite & 8 & $(1.44-21.63)$ & $5.56 \pm 0.86$ & $(3.25-27.91)$ & $12.66 \pm 1.19$ \\
\hline Abo-Homos & 8 & $(2.51-15.94)$ & $7.80 \pm 0.49$ & (BDL-8.19) & $6.38 \pm 0.28$ \\
\hline Abo El-Matamir & 9 & $(1.88-24.02)$ & $8.05 \pm 0.80$ & (BDL-10.11) & $5.24 \pm 0.37$ \\
\hline Alexandria & 6 & (BDL-5.30) & $4.01 \pm 0.15$ & $(3.04-6.98)$ & $4.99 \pm 0.27$ \\
\hline G. mean & - & - & $6.35 \pm 1.92$ & - & $7.32 \pm 3.61$ \\
\hline LSD 0.05 & - & - & 3.61 & - & 1.92 \\
\hline
\end{tabular}

BDL=below detection limit; $n=$ number of samples for each location.

GC-MS chromatogram of pendimethalin (Fig. 2a) illustrates the separation of parent compound at a retention time; 16.28 min followed by mass spectrum (Fig. 2b) showing the molecular ion $\mathrm{M}^{+}$(281.3). The fragmentation pattern might be done to the reactions $\mathrm{m} / \mathrm{z} 281 \rightarrow \mathrm{m} / \mathrm{z} 252$ as a basic ion $\left(\mathrm{M}^{+}-\mathrm{NO}\right) \rightarrow \mathrm{m} / \mathrm{z} 236\left(\mathrm{M}^{+}-\mathrm{NO}_{2}\right)$ and followed by sequences in decomposition pattern to ions; $\mathrm{m} / \mathrm{z}$ 191, 162, 145, 131, 119 and 104 as described by Moza et al. (1992). However, derivatized products of glyphosate were observed under GC separation and detection on mass spectrometer at retention times; 3.00, 3.64, and 5.20 min, respectively, (Fig. 3a), followed by their fragmentation pattern (Fig. 3b). Fluoracylimidzoles is the mode which conducted for glyphosate confirmation on GC-MS. Derivatization reaction for amine compounds give the main products (imidazole and/or N-methyl trifluoroacetamide) (Fig. 3c and d) which are thermal stable as described by Kataoka (2005).

\section{Individual's characteristics in correlation with herbicides.}

The correlation between the measured herbicides and individual's characteristics were evaluated. The correlation concern herbicide concentrations with lactational mother's age categories are illustrated in Fig. 4. Groups aged $\leq 20$ $\mathrm{yr}$ and (20-25 yr) accounted for $37.5 \%$ in Shobrakhite location with mean concentrations; $7.52,8.46 \mu \mathrm{g} / \mathrm{ml}$ and $21.73,3.69 \mu \mathrm{g} / \mathrm{ml}$ for glyphosate and pendimethalin, respectively. Other age categories did not exceed $12.5 \%$. Despite group aged $\leq 20 \mathrm{yr}$ accounted for $12.5 \%$ in Abo Homos, pendimethalin exhibited the greatest mean concentration; $15.94 \mu \mathrm{g} / \mathrm{ml}$. However, group aged $\leq 25-\leq 30$ yr accounted for $50.0 \%$ arising the greatest concentration of glyphosate; $7.41 \mu \mathrm{g} / \mathrm{ml}$. Age categories of Abo El-Matamir location

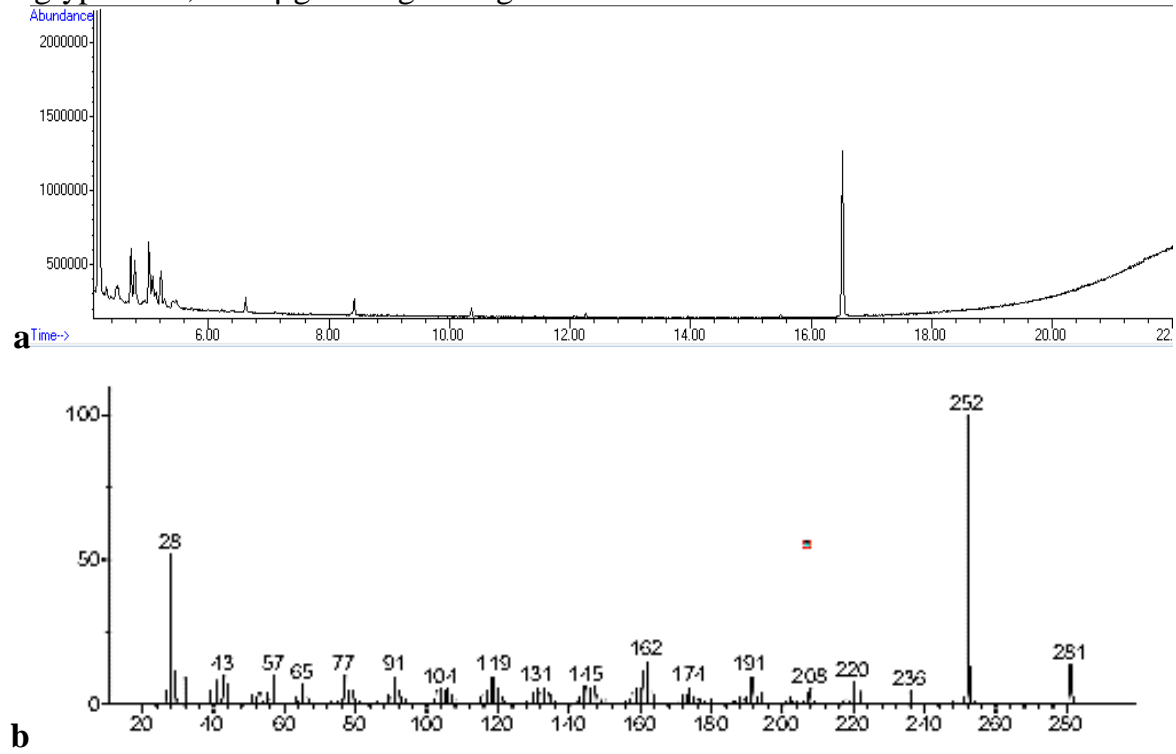

Fig 2:-illustrating (a) GC-MS chromatogram and (b) mass spectrum of herbicide; pendimethalin. 
a
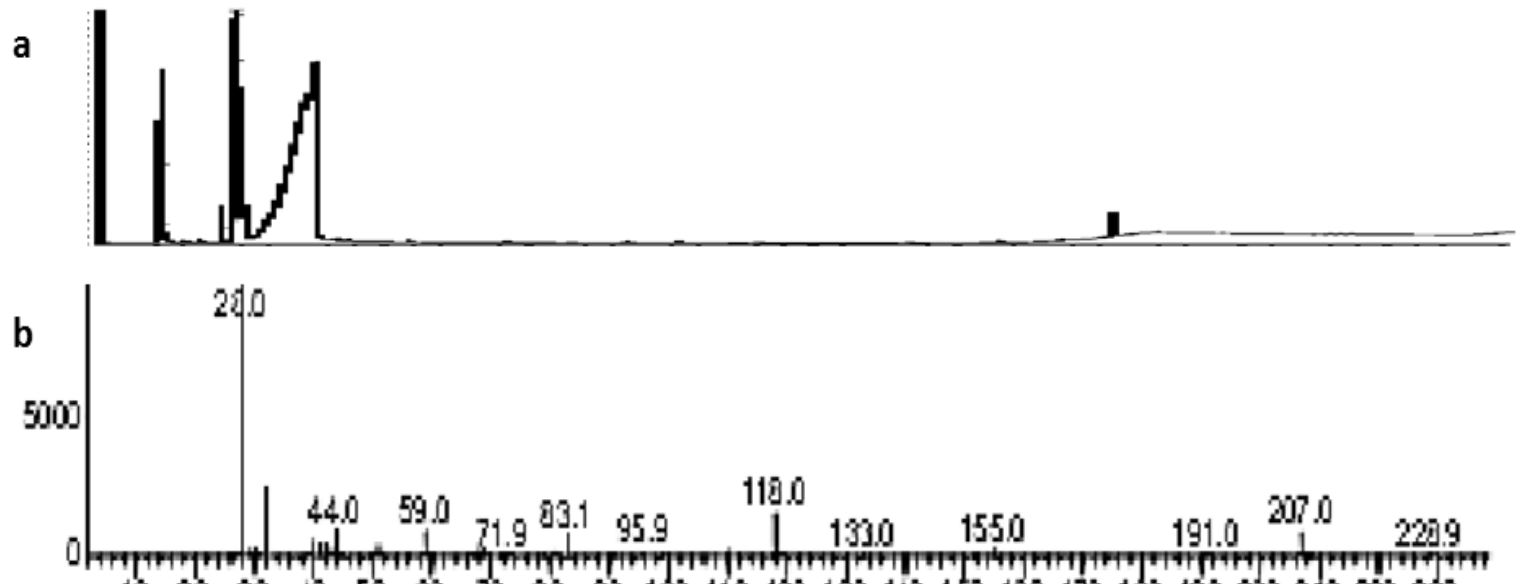

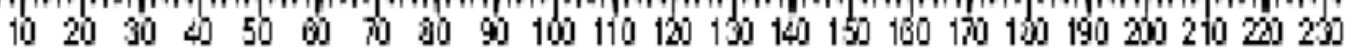
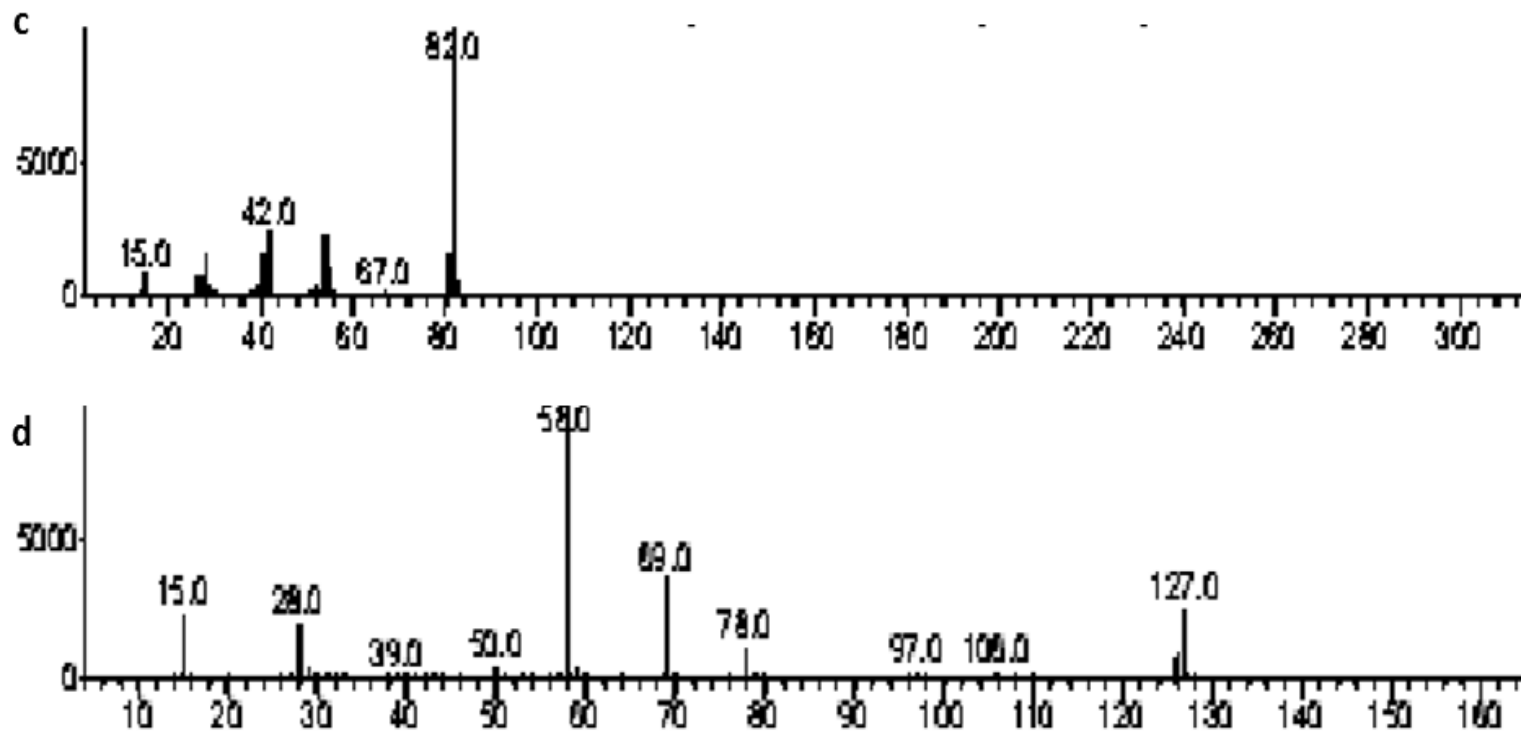

Fig 3:- Illustrating (a) GC-MS chromatogram of glyphosate-derivatized products, (b) spectrum pattern of glyphosate-derivatized products, (c) spectrum pattern of the main product 1 , imidazole, and (d) the product $2, \mathrm{~N}$ methyl trifluoroacetamide, respectively.

exhibited the greatest percentage; $62.5 \%$ for the above group with mean concentrations; 8.14 and $12.85 \mu \mathrm{g} / \mathrm{ml}$ for glyphosate and pendimethalin, respectively. In reference location (Alexandria), groups (20-25 yr) and (25-30 yr) accounted for 33.33 and $66.67 \%$ with mean concentrations; 4.68, 5.30 and 5.15, 3.58 $\mu \mathrm{g} / \mathrm{ml}$ for glyphosate and pendimethalin, respectively. In fact, glyphosate and pendimethalin were negatively associated with mothers age ( $\mathrm{r}=-$ $0.272^{*}$ and -0.111). The mean ages of locations were in the order as follows: Shobrakhite $<$ Abo Homos $<$ Abo ElMatamir < Alexandria with values: 23.75, 25.00, 29.44 and $27.17 \mathrm{yr}$, respectively. These age categories exhibited locational mean concentrations; 12.66, 6.38, 5.24, $4.99 \mu \mathrm{g} / \mathrm{ml}$ and 5.56, 7.80, 8.05, 4.01 $\mu \mathrm{g} / \mathrm{ml}$ for glyphosate and pendimethalin, respectively. 

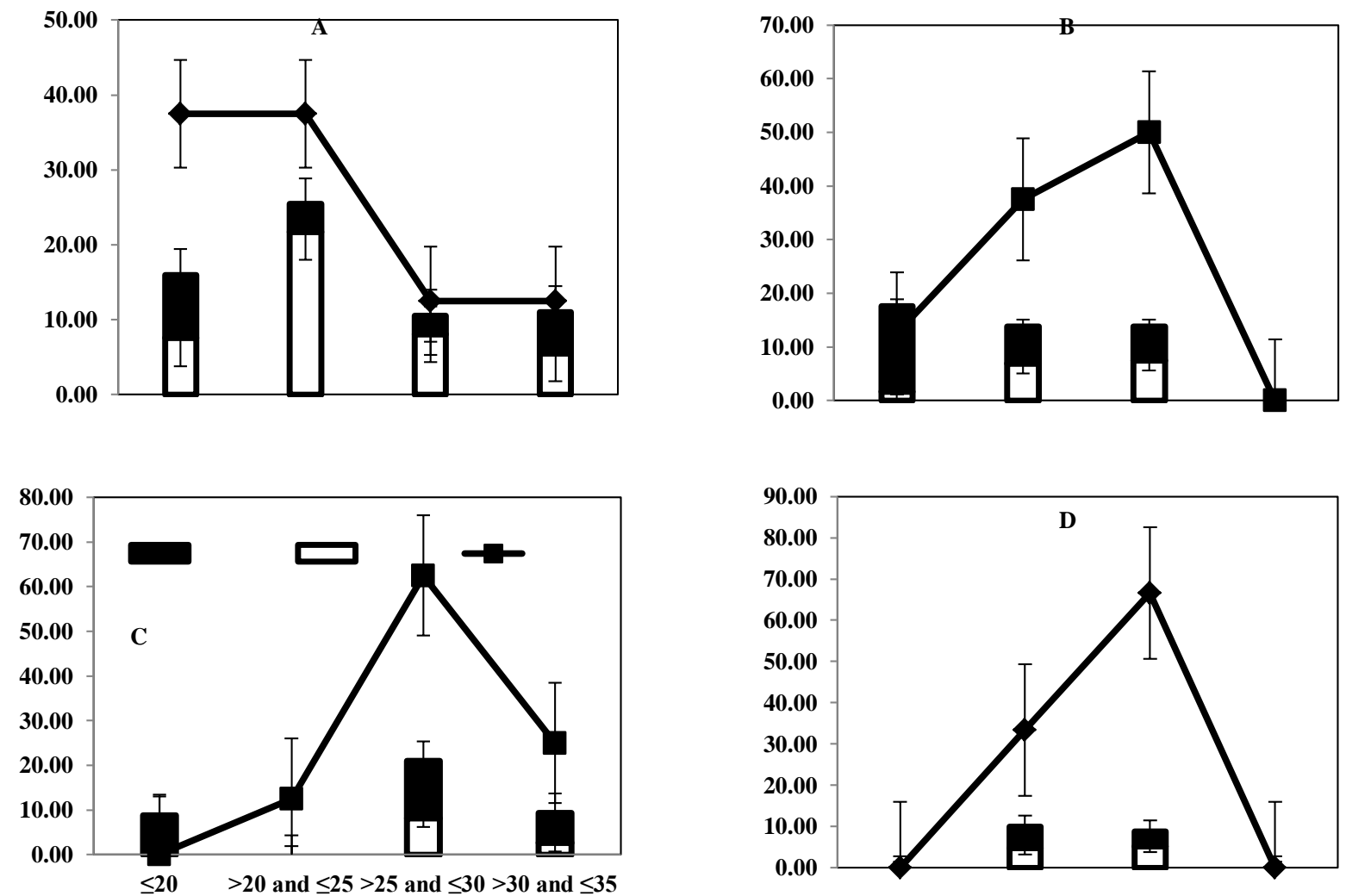

Age catagories \%

Fig 4:-The correlation between herbicide concentrations in human milk and mother age categories in (A) Shborakhit, (B) Abo-Homos, (C) Abo El-Matamir and (D) Alexandria, respectively, $(P<0 \cdot 05)$

Consumption frequency for the main diets of studied individuals indicated that, fruits exhibited the greatest percentage $87.5 \%$ in moderate level for Abo Homos residents followed by residents of Shobrakhite (75.0\%), but individuals of Abo El-Matamir recorded percentage; $75.0 \%$ at a high level of consumption. Vegetables exhibited the greatest percentage at high level for individuals of Shobrakhite and Abo Homos locations (100.0 and 87.5\%). Moderate level of consumption exhibited the greatest percentages; 75.0 and $83.33 \%$ for individuals of Abo ElMatamir and Alexandria locations. Significant different was observed for cereal's consumption. In low level, the greatest percentage; $83.33 \%$ was recorded in Alexandria. In moderate level, the greatest value, $75.0 \%$ was recorded in Abo El-Matamir location. In high level, the greatest percentages; 100.00 and $87.5 \%$ were recorded in Shobrakhite and Abo Homos, respectively. Milk and its products exhibited the greatest percentage; 100.0 and $87.5 \%$ (Moderate consumption) for individuals of Shobrakhite and Abo Homos locations. In high level, the greatest percentages 75.0 and $83.33 \%$ were recorded for individuals of Abo El-Matamir and Alexandria locations. Meat and fish consumption in rural locations exhibited low and moderate levels compared with Alexandria location (Table 2).

Table 2:-Dietary status and personal information of studied mothers.

\begin{tabular}{|l|l|l|l|l|l|}
\hline \multirow{2}{*}{ Items } & \multirow{2}{*}{ consume } & \multicolumn{5}{|c|}{ \% of dietary intake } \\
\cline { 3 - 6 } & & Shobrakhit & Abo-Homos & Abo El-Matamir & Alexandria \\
\hline Fruit & Low & 0.00 & 0.00 & 0.00 & 16.67 \\
\hline & & & & & \\
\hline & & & & & \\
\hline & Moderate & 75.00 & 87.50 & 25.00 & 33.33 \\
\hline & high & 25.00 & 12.50 & 75.00 & 66.67 \\
\hline Vegetable & Low & 0.00 & 0.00 & 0.00 & 16.67 \\
\hline & Moderate & 0.00 & 12.50 & 75.00 & 83.33 \\
\hline
\end{tabular}




\begin{tabular}{|l|l|l|l|l|l|}
\hline & high & 100.00 & 87.50 & 25.00 & 0.00 \\
\hline $\begin{array}{l}\text { Cereal and } \\
\text { products }\end{array}$ & Low & 0.00 & 0.00 & 0.00 & 83.33 \\
\hline & Moderate & 0.00 & 12.50 & 75.00 & 16.67 \\
\hline & high & 100.00 & 87.50 & 25.00 & 0.00 \\
\hline $\begin{array}{l}\text { Milk+ its } \\
\text { Products }\end{array}$ & Low & 0.00 & 0.00 & 0.00 & 0.00 \\
\hline & Moderate & 100.00 & 87.50 & 25.00 & 16.67 \\
\hline & high & 0.00 & 12.50 & 75.00 & 83.33 \\
\hline Meats & Low & 100.00 & 87.50 & 25.00 & 16.67 \\
\hline & Moderate & 0.00 & 12.50 & 75.00 & 33.33 \\
\hline & high & 0.00 & 0.00 & 0.00 & 50.00 \\
\hline Fish & Low & 100.00 & 87.50 & 25.00 & 0.00 \\
\hline & Moderate & 0.00 & 12.50 & 75.00 & 50.00 \\
\hline & high & 0.00 & 0.00 & 0.00 & 50.00 \\
\hline Sampling ratio & - & 26.67 & 26.67 & 26.67 & 20.00 \\
\hline Average age (yr) & - & 23.75 & 25.00 & 29.44 & 27.17 \\
\hline $\begin{array}{l}\text { Average No. of } \\
\text { infant }\end{array}$ & - & 1.63 & 1.75 & 2.00 & 1.67 \\
\hline
\end{tabular}

Regarding the correlations between herbicide concentrations and individual's intake, glyphosate was positively associated with vegetables $\left(\mathrm{r}=0.273^{*}\right)$, cereals $\left(\mathrm{r}=0.294^{*}\right)$, and meats $(\mathrm{r}=0.055)$ and negatively with fruits $(\mathrm{r}=0.020)$, milk and its products $\left(\mathrm{r}=-0.266^{*}\right)$, and fish $\left(\mathrm{r}=-0.304^{*}\right)$, respectively. Pendimethalin was positively associated with fruits $(r=0.084)$, milk and its products $\left(r=0.243^{*}\right)$, meat and fish $(r=0.055)$, respectively, and negatively associated with vegetables $\left(\mathrm{r}=-0.215^{*}\right)$ and cereals $(\mathrm{r}=-0.055)$.

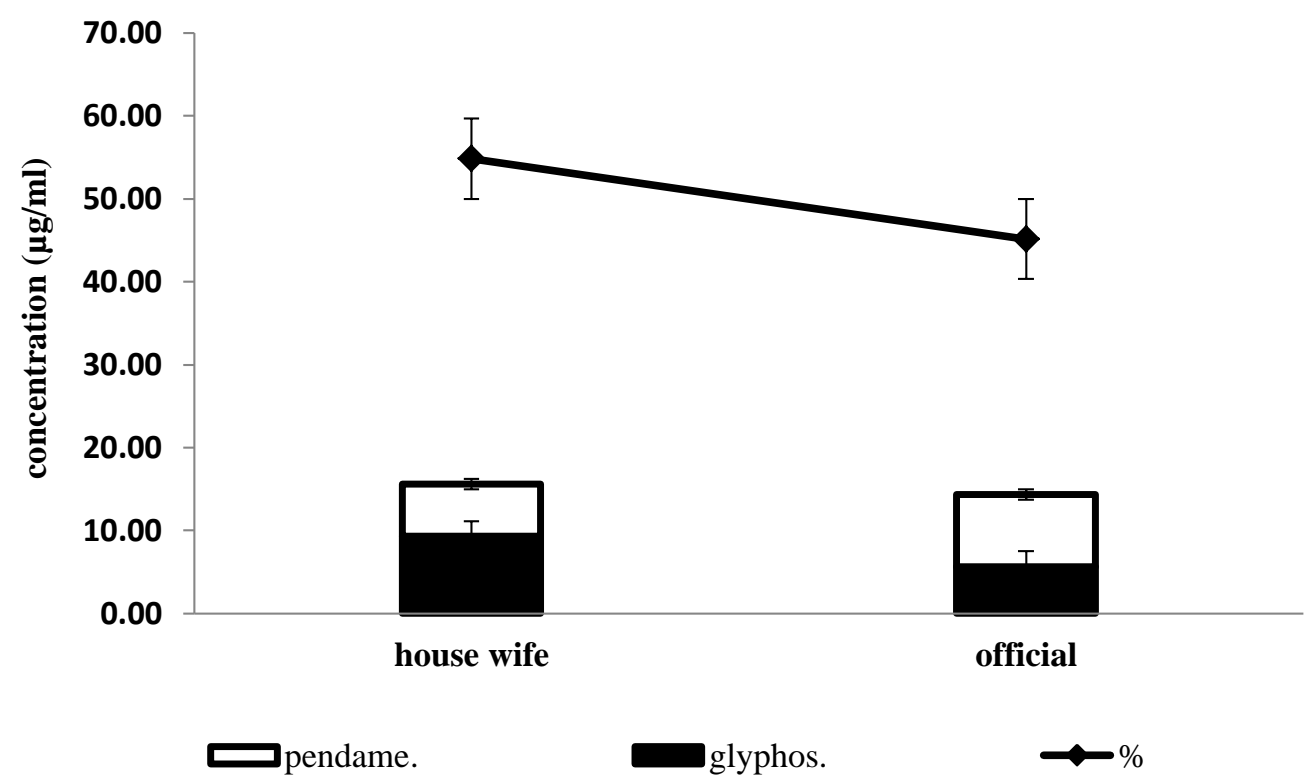

Fig 5:-The correlation between concentrations of herbicide and mother job.

Regarding mother's job, the individuals subjected to 54.84 and $45.16 \%$ for house wife and official. Most of house wife individuals live in rural locations, where their samples exhibited mean concentrations of 9.32 and $6.28 \mu \mathrm{g} / \mathrm{ml}$ for glyphosate and pendimethalin, respectively. However, official individuals exhibited mean concentrations of 5.66 and $8.71 \mu \mathrm{g} / \mathrm{ml}$ (Fig. 5). Glyphosate was negatively associated with mother's job ( $\left.\mathrm{r}=-0.330^{*}\right)$, but pendimethalin was positively associated with it $(\mathrm{r}=0.153)$. The correlation between herbicide concentrations and No. of child or infants was negatively associated with glyphosate concentration $\left(\mathrm{r}=-0.216^{*}\right)$ and positively associated with pendimethalin $(\mathrm{r}=0.078)$ (Fig. 6). 


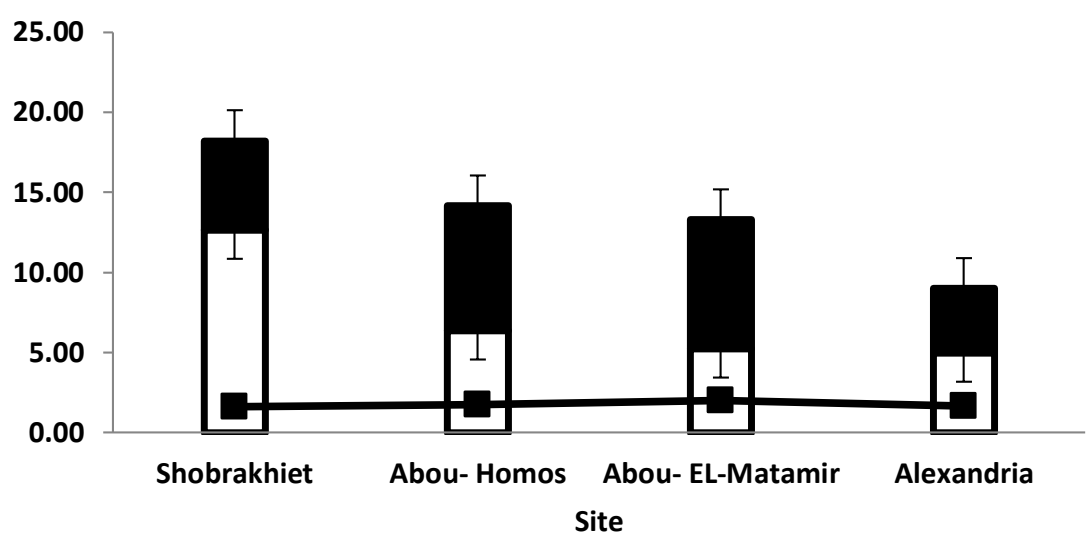

pendame. $\quad$ No. of chiled mean

TDIs

Fig 6:-The correlation between concentrations of herbicides in milk samples and No. of infant.

Estimated average daily intakes of infants for pendimethalin and glyphosate were addressed for rank of distribution at low, moderate and high levels (Table 3). Infants of Abo El-Matamir location exhibited the greatest value of TDI; $0.19,2.02$, and $8.41 \mathrm{mg} / \mathrm{kg} /$ day for pendimethalin exposure, but group of Shobrakhite location exhibited the greatest value; $0.33,3.17$ and $9.77 \mathrm{mg} / \mathrm{kg} /$ day for glyphosate. Reference location (Alexandria) exhibited the least values for both herbicides. The rank of exposure for pendimethalin at low level did not exceed $0.25 \mathrm{mg} / \mathrm{kg} / \mathrm{day}$ at $\mathrm{Abo} \mathrm{Homos}$ location, but at moderate level it ranged from 1.00 to $2.02 \mathrm{mg} / \mathrm{kg} / \mathrm{day}$. At high level, the values were 5.58, 7.57, and $8.41 \mathrm{mg} / \mathrm{kg} / \mathrm{day}$ at Abo Homos, Shobrakhite, and Abo El-Matamir location, respectively. Regarding glyphosate, rank of distribution reached values; 9.77, 2.87, and $3.54 \mathrm{mg} / \mathrm{kg} / \mathrm{day}$ for Shobrkhite, Abo Homos, and Abo ElMatamir location, compared with reference location $(2.44 \quad \mathrm{mg} / \mathrm{kg} / \mathrm{day})$.

Table 3:-Estimated daily intake (DI) of pendimethalin and glyphosate by rural infants.

\begin{tabular}{|l|c|c|c|c|c|c|}
\hline \multirow{2}{*}{ Location } & \multicolumn{5}{|c|}{ DI (mg/kg/day) } \\
\cline { 2 - 8 } & \multicolumn{2}{|c|}{ pendimethalin } & low & moderate & high \\
\cline { 2 - 8 } & low & moderate & high & low & 3.17 & 9.77 \\
\hline Shobrakhite & 0.14 & 1.39 & 7.57 & 0.33 & 1.60 & 2.87 \\
\hline Abo Homos & 0.25 & 1.95 & 5.58 & Missing data & 1.31 & 3.54 \\
\hline Abo El-Matamir & 0.19 & 2.02 & 8.41 & Missing data & 1.25 & 2.44 \\
\hline Alexandria & Missing data & 1.00 & 1.86 & 0.30 & & \\
\hline
\end{tabular}

\section{Discussion:-}

The studied herbicides are still used in Egypt at a broad spectrum against diversity of weeds. The data indicated that, both compounds have the ability to accumulate in bodies of lactating mothers through breast milk. Pendimethalin and glyphosate exhibited positive response in most milk samples from rural locations associated with their extensive practices. In addition, the impact of glyphosate in samples collected from Shobrakhite location was greater than those in other locations. This may be attributed to extensive use of herbicide on cultivated areas of fruits, citrus, beans in Shobrakhite district. Pendimethalin in Abo Homos and Abo El Matamir locations was greater than Shobrakhite, because it was extensively used to control weeds on cotton, onion, vegetables and sugar beet crops in these locations. As mentioned previously, physico-chemical properties and bio-persistence of toxicants play the main role on their transfer to infants via breast milk. In addition, there are many difficulties associated with the transfer of toxicants from mothers to their infants through milk e.g. the variable length of time that would elapse between toxicant intake, milk synthesis and sucking process (Halperin-Walega et al., 1998). Since the mammary gland is highly perfused with blood, lipophilic compounds are mostly transferred from blood to the lipid in mammary cells which in turn is secreted as milk lipid (Matthews, 1979). However, breast milk (3-5\% fat) as an 
aqueous fluid has the ability to uptake both hydrophilic and lipophilic compounds (Bouwman et al., 2006; Feo et al., 2012).

The proposed method is an alternative for the simultaneous determination of different classes of pesticides. A diversity of organic solvents and solvent mixtures were necessary to extract pesticides with different properties from the matrix. Furthermore, the method is simple, rapid, does not require sophisticated equipment. Use of solid-phase dispersion with a filter aide results in extraction and purification outputs of pesticides in one step (Palma et al., 2014). The quantification of both herbicides on liquid chromatography achieved an accurate results and good precision for the selected determination technique, especially in case of pendimethalin. However, the quantification of glyphosate residues is very challenging, because of the highly polar and amphoteric nature of the molecule, the low molecular weight, the high water solubility and the lack of chromopheres. For these reasons, glyphosate is one of the few pesticides which are not agreeable to the multiresidue methods typically employed in pesticide residue analysis (Steinborn et al., 2016). In the present study, the use of extraction method followed by dervatization by TFAA gave a sufficient response and reliable quantification of the herbicide. Additionally, confirmation technique (GC-MS) used for both herbicides offered the chance to confirm positive results.

The correlation between herbicide concentration and mother's age categories employed positive association with young individuals. The reason may be due to increase of milk secretion of young individuals, home activities and high consumption of vegetables. However, pendimethalin was positively detected in individuals whose meat and milk products were highly consumed (Alexandria location). This finding may be attributed to compound proportions on these matrix, especially which were coming from near rural areas. Similar finding was obtained for working mother, where house wife individuals achieved mean concentration of glyphosate greater than those of official individuals. Pendimethalin exhibited mean concentration greater than those of house wife individuals. On the other hand, number of children was negatively associated with concentration of glyphosate depending on mother health status concerning amounts of secreted milk and its lipophilic character as well as blood flow to mammary glands. These issues recently affected on herbicide proportions transferred to infants. Generally, sources of exposure to pesticides from mother to nursing infant are ubiquitous. It is important to recognize the potential exposures in the workplace, home and broader community and the possible routes of transmission (Heifetz and Taylor, 2015). In the home, exposure occurs in a myriad of ways; pest control activities, gardening, neighborhood drift, and agricultural pest control. In addition, the remaining levels on crops is considered the main source of exposure. On the other hand, air, water, and food are all vehicles that carry pesticides to the body, through the lung, digestive tract and/or placenta during gestation.

The present work stated that, TDI values in rural locations are greater than those of reference location (Alexandria), especially the values of glyphosate. Additionally, infants of Shobrakhite location may be exposed potential risks than others. In fact, infants may be more sensitive to the effects of chemical exposure through breast milk intake depending on different factors e.g. physiological and biochemical, chronic medical conditions, nutritional status of mother and general health status (Sonawane, 1995). Other factors increase exposure through farm work or parental occupational exposure and low socioeconomic status. Infants of poor families are more impacted highly polluted neighborhoods and have greater exposure to environmental toxicants. Therefore, the adverse effects of chemicals might be magnified in this subpopulation. Recently, low levels of toxicants at long-term exposure are the main concern with nursing infants. So, assessing the hazards of exposure to pesticides is an urgent task we face today (Sewell and Whyatt, 1989).

The WHO's International Agency for Research on Cancer (IARC) working group's 2015 decision to classify glyphosate as a grade $2 \mathrm{~A}$ probable human carcinogen followed an extensive review and evaluation of the weight of all available evidence (Guyton et al., 2015). In addition, numerous studies demonstrated that glyphosate is genotoxic and can induce oxidative stress in humans, human cells, non-human mammals and non-mammals species (IARC, 2015). Recently, there has been debate over the possibility that glyphosate is an endocrine disruptor (Walsh et al., 2000; Gasnier et al., 2009; Romano et al., 2012; Thongprakaisang et al., 2013; Amiliato et al., 2014). Studies in cell culture showed that, glyphosate induces endocrine-mediated effects on end points relevant to toxicity, as well as proliferation. In fact, European Commission extended an approval against glyphosate and glyphosate-based herbicide (GBHs) to be used under distractions and precaution. Moreover, IARC stated that current safety standards for glyphosate and GBHs are outdated and may fail to protect public health and the environment. 
On the other hand, toxicological profiles of pendimethalin were stated depending on its validity, completeness, and reliability as well as the relationship of the results of the studies to human risk (EPA, 2015). Environmental protection Agency (EPA) has also considered available information concerning the variability of the sensitivities of major identified subgroups of consumers, including infants and children. The target organ for pendimethalin is the thyroid. Thyroid toxicity in chronic and subchronic rodent's studies was manifested as alterations in the thyroid hormones (decreased total T4 and T3, increased percent of free T4 and T3), increased thyroid weight and microscopic thyroid lesions (increased thyroid follicular cell height, follicular cell hyperplasia, as well as follicular cell adenomas). On the other hand, EPA classified pendimethalin as a "Group C", possible human carcinogen based on a statistically significant increased trend and pair-wise comparison between the high-dose group and control for thyroid follicular cell adenomas in male and female rats.

For safety factor for infants and children, uncertainty/safety factors are used in compatibility with points of departure (POD) to calculate a safe exposure level-generally referred to as a population-adjusted dose (PAD) or reference dose (RfD) and safe margin of exposure (MOE). Thus, the agency estimates risk in terms of the probability of an occurrence of the adverse effect expected in a lifetime. In general, EPA shall apply an additional tenfold $(10 \mathrm{X})$ margin of safety for infants and children in the case of threshold effects to account for prenatal and postnatal toxicity and the lack of the database on toxicity.

The evaluation of potential risks to infants concern chemical residues in human milk requires consideration of a number of factors. For example, level of risk depends on each individual's food consumption patterns, nature and levels of chemical in milk and food as consumed by mothers. Although current uncertainty factors used to extrapolate toxicological data to human account for 10-fold variations between species and within the human population, additional protection may be required depending on the toxicant of interest and the amount of dietary residue monitoring and testing that has been conducted. It must be recogenized that there exist only limited data on chemical proportions in milk and food consumption patterns of infants that are appropriate to use in risk assessment (Sonawane, 1995).

\section{Summary and conclusion:-}

The present finding demonstrated a concept about impact of extensively used herbicides; glyphosate and pendimethalin on rural mothers and their infants in Egypt. Positively detection of these compounds in collected breast milk samples was conducted depending on appropriate method followed by good precision and validated chromatographic and mass spectrometric techniques. The young and house wife mothers were the most impacted with herbicides, leading to extensive lactational transfer of them. Thus, TDI of these compounds for infants of the studied participants indicate signs alarming of adverse health effects may be imposed especially that concern endocrine disorders, genotoxicity and immune toxic responses.

\section{References:-}

1. Amiliato N., Ammar D., Nezzi L., et al. (2014): Changes in ultrastructure and expression of steroidogenic factor-1 in ovaries of zebra fish Danio rerio exposed to glyphosate. J. Toxicol. Environ. Health Part A 77: 405414.

2. APC (2007): Agricultural Pesticides Committee, Pesticide Annual Report, Ministry of Agriculture, Egypt.

3. Bouwman H., Sereda B., and Meinhardt H.M. (2006): Simultaneous presence of DDT and pyrethroid residues in human milk from a malaria endemic area in South Africa. Environ. Pollut. 144(3): 902-917.

4. Burke E.R., Holden A.J. and Shaw I.C. (2003): A method to determine residue levels of persistent organochorine pesticides in human milk from Indonesian women. Chemosphere 50: 529.

5. Cohort Software Inc. (1985): Costat User Manual. Version 3 Cohort Tucson, Arisona, USA.

6. Diserens H. and Henzelin M. (1999): Determination of abamectin residues in fruits and vegetables by high performance liquid chromatography. J. Chromatography A 833: 13-18.

7. EPA (2015): Pendimethalin; Pesticide Tolerances. EPA-HQ-OPP-2014-0397 (https://wwwregulations gov/docket?D=EPA-HQ-OPP-2014-0397).

8. European Community (2003): Review report for the active substance pendimethalin. Report 7477/VI/98-final. European Commission, Health and consumer protection Directorate General, Brussels, Belgium.

9. Feo M.L., Eljarrat E., Manaca M.N., et al. (2012): Pyrethroid use-malaria control and individual applications by households for other pests and home garden use. Environ. Int. 38 (1): 67-72. 
10. Gasnier C., Dumont C., Benachour N., et al. (2009): Glyphosate-based herbicides are toxic and endocrine disruptors in human cell lines. Toxicol. 262: 184-191.

11. Guyton K.Z., Loomis D., Grosse Y., et al. (2015): Carcinogenicity of tetrachlorvinphos, parathion, malathion, diazinon and glyphosate. Lancet. Onco. 16: 490-501.

12. Halperin-Walega E., Batra V.K., Tonlli A.P., Barr A. and Yacobi A. (1998): Disposition of cefixime in the pregnant and lactating rat transfer of the fetus and nursing pups. Drug Metab. Dispost. 16: 130-138.

13. Heifetz R.M. and Taylor S.S. (2015): Mother's milk or mother's poison? Pesticides in breast milk. J. Pestic. Reform 1-6 http://eap megill ca/MagRack/JPR/JPR_07 htm.

14. IARC (2015): Glyphosate monograph some organophosphate insecticides and herbicides: diazinon, glyphosate, malathion, parathion, and tetrachlorvinphos http://monographs irac fr/ENG/Monographs/vol112/mono112-09 pdf.

15. Jensen A.A. and Slorach S.A. (1991): Chemical contaminants in human milk. Boca Raton, FI: CRC Press, 1991.

16. Kataoka H. (2005): Gas chromatography of amines as various derivatives. Quantitation of amino acids and amines by chromatography-methods and protocols. J. Chromatography 70: 364-404.

17. Khalil F., Ouda S., Osman N.A. and Ghamis A. (2011): Determination of agro-climatic zones in Egypt using a robust statistical procedure. 15th Int. Water Technol. Conf. (IWTC), Alexandria 2011, Egypt.

18. Lakritz I. and Pensabene J.W. (1984): Survey of human milk for volatile N-nitrosamines and the influence of diet on their formation. Food Chem. Toxicol. 22: 721-724.

19. Manaca M.N., Grimalt J.O., Sunyer J., et al. (2011): Concentration of DDT compounds in breast milk from African women (Manhica, Mozambique) at the early stages of domestic indoor spraying with this insecticide. Chemosphere 85 (3): 307-314.

20. Matthews H.B. (1979): Excretion of Insecticides. Pharmac. Ther. 4: 657.

21. Moza P.N., Huster S., Pal S. and Sukul P. (1992): Photocataltic decomposition of pendimethalin and alachlor. Chemosphere 25(11): 1675-1682.

22. Myers J.P., Antoniou M.N., Blumberg B., et al. (2016): Concerns over use of glyphosate-based herbicides and risks associated with exposure: a consensus statement. Environ. Health 15(19): 13.

23. Palma D.C.A., Lourencetti C., Uecker M.E., Mello P.R.B., Pignati W.A. and Dores E.F.G. (2014): Simultaneous determination of different classes of pesticides in breast milk by solid-phase dispersion and GC/ECD. J. Braz. Chem. Soc. 25(8): 1419-1430.

24. Pignati W.A., Machado J. and Cabral J.F. (2007): Major rural accident: The pesticide 'rain' case in Lucas do Rie verde city-MT. Cienc. \& Saude Coletiva 12(1): 105-114.

25. Romano M.A., Romano R.M., Santos L.D., et al. (2012): Glyphosate impairs male offspring reproductive development by disrupting gonadotropin expression. Arch. Toxicol. 86: 663-673.

26. Sewell B.H. and Whyatt R.M. (1989): Intolerable risk: Pesticides in our children's food New York: Natural Resources Defense Fund.

27. Sonawane B.R. (1995). Chemical contaminants in human milk: an overview. Environ. Health Perspect. 103 (6): 197-205.

28. Steinborn A., Alder L., Michalski B., Zomer P., Bendig P., et al. (2016): Determination of glyphosate levels in breast milk samples from Germany by LC-MS/MS and GC-MS/MS. J. Agric. Food Chem. 64: 1414-1421.

29. Thier H.P. and Zeumer H. (1987): Manual of Pesticide Residue Analysis. Verlag Chemie: New

30. Thongprakaisang S., Thiantanawat A., Rangkadilok N., et al. (2013): Glyphosate induces human breast cancer cell growth via estrogen receptors. Food Chem. Toxicol. 59: 129-136.

31. Walsh L.P., Mc Cormick C., Martin C., et al. (2000): Round up inhibits steroidogenesis by disrupting steriodogenic acute regulatory (StAR) protein expression. Environ. Health Prespect. 108: 769-776. 